\title{
Response to: Clinical Implication of Mid-Range Dynamic Instability in Lumbar Degenerative Spondylolisthesis
}

\author{
Chang-Yk Lee ${ }^{1}$, Seung-Hwan Lee ${ }^{2}$ \\ ${ }^{1}$ Department of Orthopedic Surgery, Lee Chun-Tek Orthopedic Specialty Hospital, Suwon, Korea \\ ${ }^{2}$ Department of Orthopedic Surgery, Gwangmyeong Sungae Hospital, Gwangmyeong, Korea
}

Dear Sir,

We appreciate the letter regarding our manuscript entitled "Clinical implication of mid-range dynamic instability in lumbar degenerative spondylolisthesis [1]." We thank the readers who are interested in our article and provided valuable feedback. Our reply to comments is as follows:

(1) In this study, it was important to examine whether occult movement exists and whether it is related to any other factors. Therefore, patients with increased listhesis during mid-flexion within the range of motion were important, and the values were within a significant range. The position of the leg, pelvis, extension, mid-flexion, and angle of flexion were indicated on the whole-body plate as follows, and $30^{\circ}-60^{\circ}$, including hip flexion, was assumed as the mid range. With the help of a trained imaging department, the patient was asked to fix the pelvis with the lower limbs as straight as possible and to keep them as shown in the picture (Fig. 1).

(2) It is impossible to have only the lumbar spine bent without moving the pelvis [2-6]. The meaning of midrange in this study is that the instability of lumbar can be well checked at the angle between extension and full flexion (including hip flexion).

(3) When the lumbar spine did not appear to be true

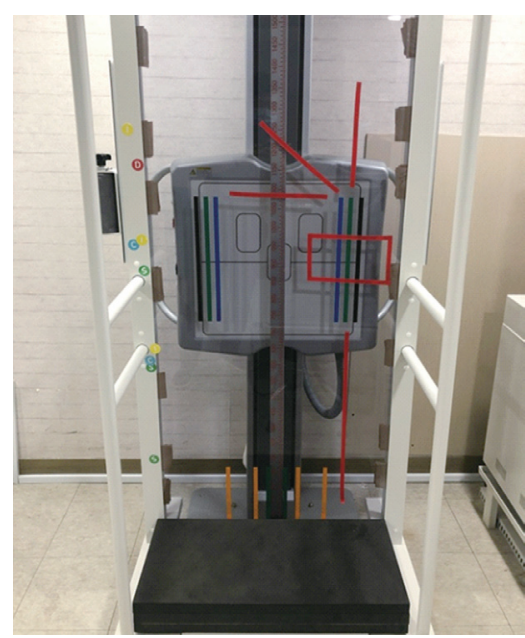

Fig. 1. The position of the leg (red straight line), pelvis (red square), extension, mid-flexion, and angle of flexion (red three lines) were indicated on the whole-body plate.

lateral only with the degenerative scoliosis, the midpoint of the two posterior vertebral lines was measured [7].

(4) The small number of patients is a limitation of this study. If the number is increased, the statistical significance will be more certain. The above information is also described in the limitation of the study by this author, and based on this, we intend to proceed further.

Received Aug 4, 2020; Accepted Aug 31, 2020

Corresponding author: Seung-Hwan Lee

Department of Orthopedic Surgery, Gwangmyeong Sungae Hospital, 36 Digital-ro, Gwangmyeong 14241, Korea

Tel: +82-2-2680-7699, Fax: +82-2-2680-7755, E-mail: java5885@gmail.com 
(5) During full flexion, the hooking mechanism of the facet joint, stretched back muscle, and posterior longitudinal ligament are thought to have reduced the vertebra [1].

\section{Conflict of Interest}

No potential conflict of interest relevant to this article was reported.

\section{ORCID}

Chang-Yk Lee: https://orcid.org/0000-0001-8780-100

Seung-Hwan Lee: https://orcid.org/0000-0002-0432-3857

\section{References}

1. Lee CY, Park BM, Kim TW, Lee SH. Clinical implication of mid-range dynamic instability in lumbar degenerative spondylolisthesis. Asian Spine J 2020;14:507-12.

2. Kapandji IA. The trunk and vertebral column. In: Kapandji IA, editor. The physiology of the joints: anno- tated diagrams of the mechanics of the human joints. 2nd ed. Edinburgh: Churchill Livingstone; 1974. p. 44-8.

3. Twomey L. The effects of age on the ranges of motions of the lumbar region. Aust J Physiother 1979;25:257-63.

4. McGregor AH, McCarthy ID, Hughes SP. Motion characteristics of the lumbar spine in the normal population. Spine (Phila Pa 1976) 1995;20:2421-8.

5. Van Herp G, Rowe PJ, Salter PM. Range of motion in the lumbar spine and the effects of age and gender. Physiotherapy 2000;86:42.

6. Trudelle-Jackson E, Fleisher LA, Borman N, Morrow JR Jr, Frierson GM. Lumbar spine flexion and extension extremes of motion in women of different age and racial groups: the WIN study. Spine (Phila Pa 1976) 2010;35:1539-44.

7. Sullivan MS, Dickinson CE, Troup JD. The influence of age and gender on lumbar spine sagittal plane range of motion: a study of 1126 healthy subjects. Spine (Phila Pa 1976) 1994;19:682-6. 